\title{
Total volume of 3D small patch reefs reflected in aerial photographs can predict total species richness of coral reef damselfish assemblages on a shallow back reef
}

Received: 19 May 2014/ Accepted: 8 April 2015/Published online: 22 April 2015

(C) The Author(s) 2015. This article is published with open access at Springerlink.com

\begin{abstract}
Because fish have a high dispersal ability, an understanding coral reef fish metacommunity structure is vital for effective conservation. Coral reefs provide patchy habitat of various sizes and scales. We examined the species-area relationship (SAR) of damselfish (Pomacentridae) assemblages over 81 environmentally homogenous patch reefs ranging $0.07-45.4 \mathrm{~m}^{2}$ with low coral cover. Patch reefs were located in the shallow back reef ( $<2.5 \mathrm{~m}$ deep) off Ishigaki Island, Japan. Reef area was measured by performing image analysis of enlarged sections of a high-resolution $(>1 / 2500)$ color aerial photograph used as a fine-scale seascape map. To assess the effects of three-dimensional meso-scale rugosity on species richness, we assumed that all reefs had a cylindrical shape and examined species by volume (area $x$ height) relationships (SVR). Patch reef volume was a better determinant of species richness than area, and the regression functions of SVR provided better estimates of patch reef species richness. Neither the observed SVRs nor SARs, however, could be explained by a random placement model alone. Our results suggest that several small reefs are likely to have higher species richness than a single large reef of equivalent area in the shallow back reef where large patch reefs are flat. Thus, total patch reef volume (area $\times$ height) better reflects meso-scale rugosity and is a useful indicator of total species richness relative to the total amount of essential habitat in shallow back reefs.
\end{abstract}

Keywords Meso-scale rugosity · Metacommunity · Seascape structure $\cdot$ SLOSS $\cdot$ Species-area relationships

\footnotetext{
A. Hattori $(\square)$

Faculty of Liberal Arts and Education, Shiga University, 2-5-1 Hiratsu, Otsu, Shiga 520-0862, Japan

E-mail: hattori@edu.shiga-u.ac.jp

T. Shibuno

Aquaculture Department, Southeast Asian Fisheries Development Center, 5021 Tigbauan, Iloilo, Philippines
}

\section{Introduction}

Unlike terrestrial animals, an understanding of metacommunity structure is vital for the conservation of sedentary marine animals because they have a dispersive larval phase that enables use of discrete habitat patches (Roff and Zacharias 2011). Coral reefs form patchy habitats for sedentary marine animals on various scales, and coral reef fish communities are among the richest animal communities in nature (Lowe-McConnell 1987; Sale 1991, 2002; Boström et al. 2011; Pittman et al. 2011). Although patterns of reef connectivity and patch dynamics are not well understood for reef fish (Christie et al. 2010; Mumby et al. 2011), evidence suggests that larval connectivity between habitat patches within a coral reef area is high (e.g., Almany et al. 2007; Planes et al. 2009; Pinsky et al. 2012).

The back reef is an essential component of a coral reef, harboring many resident reef fish (Chave and Eckert 1974; Lowe-McConnell 1987). Back reefs are often less than $3 \mathrm{~m}$ deep and consist of numerous small patch reefs formed by coral heads and outcrops dispersed throughout the sandy bottom. These patch reefs of various sizes offer a valuable means of studying the metacommunity structure of coral reef fish on a small spatial scale.

The species-area relationship (SAR) is a useful tool for terrestrial conservation because it allows an estimate of an important variable (species richness) to be made from another variable (area) that is easily measured (Rosenzweig 1995, 2004; Tjörve 2003; Dengler 2009; Smith 2010). Fahrig (2013) suggested that species richness does not increase in several small habitats relative to a single large habitat of equivalent area, but that total area, no matter how subdivided, is the crucial determinant of species richness. In contrast, Rosenzweig (2004) suggested that this single large or several small (SLOSS) debate may matter at small spatial scales because of edge effects and metapopulation dynamics. On very small 
scales, superior competitors can avoid using patch edges where predation risk is higher (Ries and Sisk 2010), and superior dispersers or colonizers can move among habitat patches using small patches and patch edges to avoid interspecific competition (Tilman 1994; Lehman and Tilman 1997; Hattori 2002). Thus, multiple species with similar habitat requirements may coexist in a patchy habitat via interspecific trade-offs between dispersal/colonization and competitive abilities (Tilman 1994; Lehman and Tilman 1997).

Marine ecologists examining the SAR in coral reef fishes across small patch reefs dispersed throughout a sandy bottom have found greater species richness in larger patch reefs (Sale and Steel 1986; McClanahan 1994; Ault and Johnson 1998; Acosta and Robertson 2002; Chittaro 2002). These findings suggest that high fish species richness on large reefs may be caused by high coral cover and topographic complexity in addition to the large area. Even if there are no differences in complexity between habitat patches, the random placement model holds that more species may be found on larger reefs simply because they may randomly accumulate larger numbers of settling species (Coleman 1981; Simberloff and Gotelli 1984). Belmaker et al. (2007) demonstrated clearly that, on a small scale, the observed SAR in coral reef fish can be reproduced using random placement model simulations (RPMS). In contrast, Harborne et al. (2012) highlighted the important influence of coral-generated meso-scale rugosity on reef fish species abundance and diversity, where tall reefs $(>0.5 \mathrm{~m})$ harbor more species than flat reefs. Accordingly, several small but tall reefs may harbor more species than a single flat (and short) reef of equivalent area. Moreover, interspecific trade-offs between dispersal and competitive abilities may affect the SAR in coral reef fish on very small spatial scales. Thus, the relationships among species richness, patch reef area (size distribution and total area), habitat complexity (coral cover and three-dimensional meso-scale rugosity) and the random placement model remains uncertain.

To determine whether single large or several small patch reefs (both in the size-distribution and the total patch reef area) affect the total species richness of fish on shallow back reefs, Hattori and Shibuno (2010) examined SARs in damselfish (Pomacentridae) assemblages on 84 small patch reefs with similar levels of low coral cover off Ishigaki Island, Okinawa, Japan. They performed RPMS to compare SARs simulated with random placement with observed SARs. Species richness was found to increase linearly with log-transformed patch reef area, but observed species richness on the largest reefs was much lower than that expected from RPMS; a single large patch reef did not harbor more damselfish species than several small patch reefs with an identical total area. Further work in the shallow back reef suggested that the effects of interspecific competition on species richness are stronger on flat reefs than on tall reefs (Hattori and Shibuno 2013). Thus, tall reefs may also harbor more species than an equivalent area of flat reefs.
We reexamined the SAR in coral reef damselfish at the same site off Ishigaki Island in Japan that was studied by Hattori and Shibuno (2010) to test previous results. We confirmed that (a) the regression function obtained from the observed SAR could predict species richness on patch reefs; (b) the SLOSS issue affected the observed SAR, where the RPMS alone could not reproduce the observed patterns; and (c) coral cover only slightly affected the observed SAR. To determine the effects of three-dimensional meso-scale rugosity on species richness, we then analyzed the SARs and species volume (area $\times$ height) relationships (SVR) in the fish. Specifically, we examined three questions: (a) can the regression function derived from the observed SVR be used to predict species richness on patch reefs? (b) Can the observed SVR be reproduced by RPMS alone? (c) Does coral cover contribute to the observed SVR? To address these questions, we counted the number of individuals of all species of damselfishes found within an area of patch reef and measured the coral cover, height and area of each reef. We then used the abundance data of each species to perform RPMS and assess the effects of SLOSS on patch reef species richness (Simberloff and Gotelli 1984; Hattori and Shibuno 2010; see below). Overall, we aimed to determine if SLOSS matters at the scale of small patch reefs with similarly low coral cover relative to interspecific trade-offs between dispersal and competitive abilities of reef fishes.

\section{Methods}

\section{Study species}

Damselfish are abundant and conspicuous in the back reef zones of coral reefs (Allen 1991). They are grazers, browsers or plankton feeders that feed near habitat refuges that provide quick escape from predators. Small patch reefs of coral heads and outcrops, the most common damselfish habitat, serve multiple purposes, providing food, mating sites and spawning grounds. Thus, damselfish assemblages are ideal for estimating the habitat quality of small patch reefs.

\section{Study site and seascape maps}

Research was conducted between June and September 2009 in the shallow (1.5-2.5 m), sandy back reef zone of Shiraho Reef, Ishigaki Island, Okinawa, Japan $\left(24^{\circ} 22^{\prime} 18.22 \mathrm{~N}, 124^{\circ} 15^{\prime} 13.82 \mathrm{E}\right)$. The site (3.6 ha) was the same as that used by Hattori and Shibuno (2010), which we divided the site into the same seven districts (see also Tamura et al. 2007; Hattori 2012). The shallow back reef contains numerous small patch reefs $\left(0.05-45.4 \mathrm{~m}^{2}\right)$ that are easily distinguished in high-resolution color aerial photographs. These aerial photographs were waterproofed and used as seascape maps for data collection (methods in Hattori and Shibuno 2010). Coral cover and 
forms (digitate, massive, branching, pillar or encrusting) of 81 patch reefs were sketched underwater on the maps in August 2009. Three reefs $0.05-0.18 \mathrm{~m}^{2}$ measured in 2007 (Hattori and Shibuno 2010) were no longer present.

\section{Data collection and analysis}

Damselfish species and abundance were counted at all measured patch reefs six times, and the mean value was taken as the observed total species richness. The observed SAR for each patch reef was then calculated as the relationship between the mean damselfish species richness and reef area. Data were collected as in Hattori and Shibuno (2010), where the position of each damselfish was recorded directly onto the fine-scale seascape map using its species name. Two snorkelers individually conducted a census at two or three districts per day for a total of six counts in each district (three per snorkeler) in a 1-week period during late June 2009. We then averaged the numbers of individuals of each species observed on each patch reef. The basal area and coral cover of each patch reef were determined using Image $\mathrm{J} 1.33$ (Rasband, W.S. Image J, US. National Institutes of Health, Bethesda, Maryland, USA, http://rsb.info.nih. gov/ij/, 1997-2007) according to the methods detailed in Hattori and Shibuno (2010). Reef height to the nearest $5 \mathrm{~cm}$ was previously measured in the field (Hattori and Shibuno 2013). All data were analyzed with the statistical software R 3.0.1 (R Development Core Team 2013). Comparisons between data collected in 2009 (this study) and 2007 (Hattori and Shibuno 2010) were examined using a t-test for the mean species richness and the total damselfish abundance, and paired t-test for the mean percent coral cover. Linear functions were fitted to the SAR and SVR data in semi-log space. Observed SVR of each patch reef was calculated as the relationship between its average damselfish species richness and reef volume (area $\times$ height), assuming a cylindrical shape for each reef. Observed SVRs were calculated for the data collected in both 2007 (Hattori and Kobayashi 2010) and 2009. Pearson correlation coefficients were used to estimate the relationship between patch reef species richness and total area of coral cover. Non-linear regressions were used to estimate the relationship between species richness, percent coral cover and patch reef area or volume. We compared the number of patch reefs inhabited by each damselfish species to evaluate the presence of interspecific trade-offs between dispersal and competitive abilities.

\section{Random placement model simulation (RPMS)}

To estimate the effect of patch reef size (i.e. SLOSS) on the observed SAR and SVR in damselfish, we performed computer simulations using the abundance data for each species according to the methods detailed in Hattori and
Shibuno (2010). In the computer simulations, we assumed that there are no interspecific competitions on each reef and no differences in habitat complexity between reefs and consequently larger patch reefs randomly accumulate larger numbers of settling individuals. Accordingly, greater species richness is expected to be found at larger reefs under these conditions (see also Coleman 1981; Simberloff and Gotelli 1984; Belmaker et al. 2007). Thus, in the random placement model, SLOSS does not affect SAR. In order to know whether SAR can be explained by random placement alone and is unaffected by SLOSS, we compared the observed SAR with the results from RPMS. In the computer simulations, individuals of each species were reshuffled among reefs with a settling probability proportional to the relative area or volume of the reef. Individuals were assumed to settle from an external pool without interactions or competition. This procedure was repeated for the total number of individuals in each species, and the number of species at each patch reef was counted. Simulations were repeated 10,000 times, and the average species richness and standard deviation were calculated for each reef. RPMS results were then plotted in semi-log space and compared with the observed SAR or SVR by fitting regression functions to the data. Because computer-generated random placement curves often show a cubic curve (Belmaker et al. 2007), third order polynomial regression functions were used.

\section{Results}

\section{Observed SAR and results from RPMS}

Six censuses of the 81 patch reefs (ranging $0.07-45.4 \mathrm{~m}^{2}$ ) in 2009 yielded means of 2734.5 individuals comprising 21.5 species of damselfish. In comparison, 2007 censuses of the 84 patch reefs found 2531.2 individuals of 23.2 species on average (Table 1, see also Hattori and Shibuno 2010). There was a significant difference in mean total species richness between years $(t=4.4$, $P=0.0014)$ but not in the mean total number of individuals $(t=0.9, P=0.388)$. The composition of rare species had changed in 2009 such that four species found in 2007 had disappeared and three new species had appeared.

Similarly to the results of Hattori and Shibuno (2010), the semi-log plot of SAR was linear $\left(\mathrm{R}^{2}=0.601, F=119.0, P<0.0001\right.$, AIC $\left.=331.1\right)$, with a highly significant slope and intercept (Fig. 1; slope $t=10.9, \quad P<0.0001 ; \quad$ intercept $t=21.8$, $P<0.0001$ ), suggesting that the observed SAR could be used to predict species richness on a patch reef. In contrast, the expected species richness (13.5) extrapolated from the total patch reef area $\left(165.69 \mathrm{~m}^{2}\right)$ was substantially lower than the observed species richness (21.5). The observed SAR was within 2 SD of RPMS results for small and medium sized reefs, but not for large reefs (Fig. 1); thus, these findings substantiated 
Table 1 Average abundance (recorded in six censuses) and feeding strategies of damselfish species across 81 (2009) and 84 surveyed patch reefs (2007), as well as the number of reefs on which each species was found

\begin{tabular}{|c|c|c|c|c|c|c|}
\hline & \multirow[t]{2}{*}{ Scientific name } & \multicolumn{2}{|c|}{ Abundance } & \multicolumn{2}{|c|}{$\begin{array}{l}\text { Patch reefs } \\
\text { inhabited }\end{array}$} & \multirow[t]{2}{*}{ Feeding strategy } \\
\hline & & 2009 & 2007 & 2009 & 2007 & \\
\hline 1. & Chromis viridis & 561.8 & 321.3 & 20 & 21 & $\mathrm{P}$ \\
\hline 2. & Chrysiptera cyanea & 543.8 & 715.7 & 42 & 45 & $\mathrm{P}$ \\
\hline 3. & Dascyllus aruanus & 481.3 & 545.2 & 51 & 57 & $\mathrm{P}$ \\
\hline 4. & Amblyglyphidodon curacao & 431.1 & 149.7 & 46 & 31 & $\mathrm{P}$ \\
\hline 5. & Pomacentrus adelus & 221.0 & 264.2 & 70 & 69 & A \\
\hline 6. & Stegastes nigricans & 157.8 & 133.8 & 42 & 48 & AA \\
\hline 7. & Pomacentrus moluccensis & 147.3 & 151.2 & 38 & 40 & A \\
\hline 8. & Stegastes lividus & 55.3 & 70.8 & 18 & 23 & AA \\
\hline 9. & Amphiprion frenatus & 30.5 & 32.2 & 11 & 16 & A \\
\hline 10. & Amblyglyphidodon leucogaster ${ }^{\mathrm{a}}$ & 19.3 & 6.7 & 7 & 5 & $\mathrm{P}$ \\
\hline 11. & Pomacentrus amboinensis & 19.0 & 19.2 & 30 & 18 & A \\
\hline 12. & Hemiglyphidodon plagiometopon & 13.8 & 10.0 & 17 & 10 & AA \\
\hline 13. & Dischistodus prosopotaenia & 12.5 & 19.2 & 24 & 28 & AA \\
\hline 14. & Cheiloprion labiatus & 12.0 & 40.8 & 14 & 26 & $\mathrm{C}$ \\
\hline 15. & Pomacentrus chrysurus & 9.7 & 9.7 & 17 & 18 & AA \\
\hline 16. & Abudefduf sexfasciatus & 7.8 & 27.0 & 13 & 17 & $\mathrm{P}$ \\
\hline 17. & Amphiprion ocellaris & 3.0 & 3.0 & 1 & 1 & A \\
\hline 18. & Dascyllus reticulatus ${ }^{\mathrm{a}}$ & 1.8 & 0 & 3 & 0 & $\mathrm{P}$ \\
\hline 19. & Chrysiptera rex $x^{\mathrm{a}}$ & 1.7 & 2.3 & 3 & 5 & A \\
\hline 20. & Abudefduf vaigiensis & 1.3 & 0.8 & 1 & 1 & $\mathrm{P}$ \\
\hline 21. & Neoglyphidodon nigroris ${ }^{\mathrm{a}}$ & 1.0 & 2.8 & 1 & 4 & A \\
\hline 22. & Pomacentrus nagasakiensis $^{\mathrm{a}}$ & 1.0 & 0 & 1 & 0 & $\mathrm{P}$ \\
\hline 23. & Abudefduf septemfasciatus ${ }^{\mathrm{a}}$ & 0.3 & 0 & 1 & 0 & $\mathrm{P}$ \\
\hline 24. & Neoglyphidodon melas & 0 & 3.3 & 0 & 5 & $\mathrm{~S}$ \\
\hline 25. & Chrysiptera biocellata ${ }^{\mathrm{a}}$ & 0 & 1.0 & 0 & 1 & A \\
\hline 26. & Pomacentrus bankanensis ${ }^{\mathrm{a}}$ & 0 & 0.8 & 0 & 2 & A \\
\hline 27. & Plectroglyphidodon dickii ${ }^{\mathrm{a}}$ & 0 & 0.5 & 0 & 1 & A \\
\hline
\end{tabular}

Data from 2007 was taken from Hattori and Shibuno (2010)

$P$ mainly planktivores, $A A$ mainly algivores, $A$ feeds on algae and others, $C$ corallivores, $S$ feeds on soft coral polyps

${ }^{\text {a }}$ Only juveniles were found

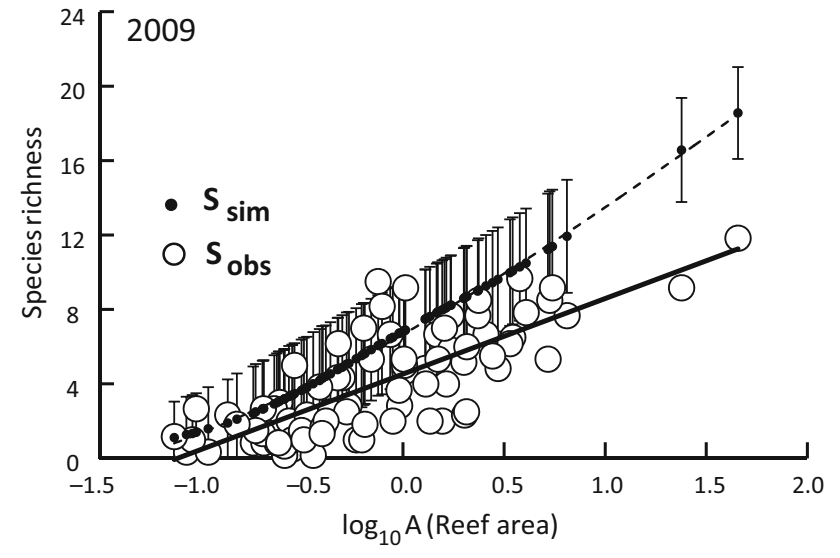

Fig. 1 Observed species-area relationships (SAR, large open circles) on patch reefs and the results of random placement model simulations (RPMS, $n=10,000)$ plotted on a semi-log scale. Solid points with vertical lines indicate simulated mean species richness \pm 2 standard deviations. The regression line represents observed SAR $\left(\mathrm{S}_{\mathrm{obs}}=4.0586 \times \log _{10} \mathrm{~A}+4.5247, \quad \mathrm{R}^{2}=\right.$ $0.6011)$, and the broken regression curve represents the simulation results $\left(\mathrm{S}_{\mathrm{sim}}=-0.1109 \times \log _{10} \quad \mathrm{~A}^{3}+0.7634 \times \log _{10} \quad \mathrm{~A}^{2}+\right.$ $\left.6.1794 \times \log _{10} \mathrm{~A}+6.6597, \mathrm{R}^{2}=0.9986\right)$ those of Hattori and Shibuno (2010) that the observed SAR could not be explained by a random placement model alone.

The cubic order polynomial regression curve showed a good fit to the RPMS of the SAR (Fig. $1, \mathrm{R}^{2}=0.999$, $F=18830, \quad P<0.0001, \quad$ AIC $=-99.0)$. The extrapolated species richness (23.0 species) obtained from the regression curve was similar to the observed total species richness (21.5). Thus, like Hattori and Shibuno (2010), total species richness could be predicted from total patch reef area using the polynomial regression function obtained from RPMS.

\section{Effect of coral cover on observed SAR}

Overall, percent coral cover was $6 \%$ lower in 2009 than in 2007 at $26.2 \pm 27.3 \%$ (mean $\pm \mathrm{SD})(t=-2.20$, $P=0.031, n=81$ ). As in 2007, the total area of coral cover was greatest in the largest two reefs, although the percent coral cover (28.4 and $20.2 \%$, respectively) was not the highest observed. Species richness showed a significant positive correlation with the total area of coral 
cover $(r=0.487, t=4.96, P<0.001, n=81)$ but did not correlate with percent coral cover $(r=0.002$, $t=0.019, P=0.985, n=81)$. A model including the $\log$ of the area, coral cover $(\%)$, and the interaction term as the predictors significantly explained observed species richness $\left(\mathrm{S}_{\text {obs }}\right)$ on a patch reef $\left(\mathrm{R}^{2}=0.669, F=51.8\right.$, $P<0.0001$, AIC $=320.0)$, giving the following equation: $\mathrm{S}_{\mathrm{obs}}=3.6598+3.2395 \times \log$ area $+4.0199 \times$ coral cover $(\%)+4.340 \times \log$ area $\times$ coral cover $(\%)$. The interaction term was significant $(F=7.51$, $P<0.01)$. The coefficient of determination was $6.08 \%$ higher than that found using a semi-log plot of SAR without percent coral cover and the interaction term. Thus, as found in Hattori and Shibuno (2010), coral cover showed only a slight effect on SAR.

\section{Observed SVRs and results from RPMS}

The semi-log plots of SVR were linear for both 2007 $\left(\mathrm{R}^{2}=0.717, F=207.4, P<0.0001, \quad\right.$ AIC $\left.=332.6\right)$ and $2009\left(\mathrm{R}^{2}=0.620, \quad F=129.0, \quad P<0.0001\right.$, AIC = 327.1; Fig. 2), with highly significant slopes and intercepts in both years (Fig. 2; 2007, slope $t=14.4$, $P<0.0001$; intercept $t=4.1, P<0.0001 ; 2009$, slope $t=11.4, P<0.0001$; intercept $t=2.8, P=0.007$ ). Although these analyses suggested that the observed SVR could be used to predict patch reef species richness, the expected species richness (13.9 in 2007; 12.1 in 2009) calculated from total patch reef volume $\left(24028.1 \mathrm{~m}^{3}\right.$ in 2007; $24015.3 \mathrm{~m}^{3}$ in 2009) was much lower than observed total species richness in both years (23.2 in 2007; 21.5 in 2009). Similarly to SAR, the observed SVRs were within 2 SD of simulated values for small reefs, but not for large reefs. Thus, a random placement model alone did not explain observed SVRs.

Cubic order polynomial regression curves showed a good fit to the SVRs $\left(2007 \mathrm{R}^{2}=0.999, F=47100\right.$, $P<0.0001$, AIC $=-139.6 ; 2009 \mathrm{R}^{2}=0.999, F=$ $18000, P<0.0001,-71.7)$. Extrapolated species richness ( 23.0 for $2007 ; 21.9$ for 2009 ) was very similar to the mean observed values (23.2 for $2007 ; 21.5$ for 2009 ; Fig. 2), indicating total species richness could be predicted from total patch reef volume using RPMS.

\section{Effect of coral cover on observed SVR}

The model of patch reef species richness with log volume, coral cover $(\%)$ and the interaction term as predictors was significant for both $2007\left(\mathrm{R}^{2}=0.770\right.$, $F=89.5, \quad P<0.0001, \quad$ AIC $=318.9) \quad$ and 2009 $\left(\mathrm{R}^{2}=0.683, F=55.2, \quad P<0.0001, \quad\right.$ AIC $\left.=316.6\right)$. Only the interaction terms (2007 $t=2.515, P=0.014$; $2009 t=2.607, P=0.011)$ and slopes $(2007 t=6.239$, $P<0.001 ; 2009 t=6.626, P<0.001)$ were statistically significant.

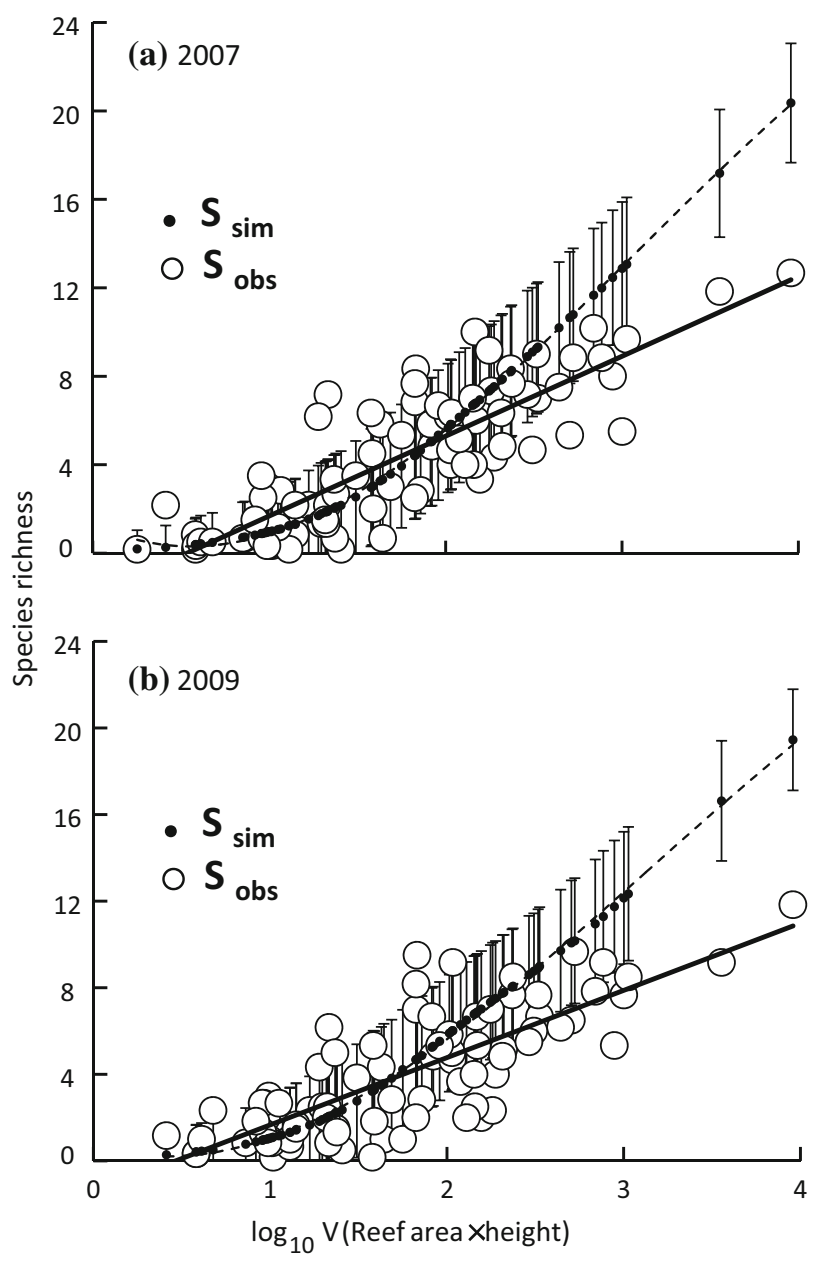

Fig. 2 Observed species-volume relationships (SVR, large open circles $)$ on patch reefs and the results of RPMS $(n=10,000)$ plotted on a semi-log scale in 2007 (a) and 2009 (b). Solid points with vertical lines indicate simulated mean species richness \pm 2 standard deviations. The regression lines represent observed SVRs (2007, $\mathrm{S}_{\mathrm{obs}}=3.6113 \times \log _{10} \quad \mathrm{~V}-1.9293, \quad \mathrm{R}^{2}=0.717 ; 2009, \quad \mathrm{~S}_{\mathrm{obs}}=$ $\left.3.1075 \times \log _{10} \mathrm{~V}-1.4439, \mathrm{R}^{2}=0.620\right)$, and the broken regression curves represent simulation results $\left(2007, \mathrm{~S}_{\mathrm{sim}}=-0.4081 \times \log _{10}\right.$ $\mathrm{V}^{3}+3.7951 \times \log _{10} \mathrm{~V}^{2}-3.8397 \times \log _{10} \mathrm{~V}+1.3377, \mathrm{R}^{2}=$ $0.9994 ; 2009, \quad \mathrm{~S}_{\text {sim }}=-0.3259 \times \log _{10} \mathrm{~V}^{3}+3.0740 \times \log _{10} \mathrm{~V}^{2}$ $\left.2.3787 \times \log _{10} \mathrm{~V}+0.691, \mathrm{R}^{2}=0.9986\right)$

Species distributions across patch reefs

The four most abundant species in 2009 were Chromis viridis, Chrysiptera cyanea, Dascyllus aruanus and Amblyglyphidodon curacao, all of which are planktivores. The next four most abundant (Pomacentrus adelus, Stegastes nigricans, Pomacentrus moluccensis and Stegastes lividus) are herbivores (Table 1). The planktivores constituted $73.8 \%$ of all individuals, and the top eight species constituted $95.1 \%$. In both years, C. viridis and S. lividus were found at only $22-27 \%$ of patch reefs, whereas C. cyanea, D. aruanus, P. adelus and S. nigricans were present in more than half of all reefs. 


\section{Discussion}

Our results demonstrated that a logarithmic regression function of the observed SAR can be used to predict patch reef species richness, corroborating our previous work (Hattori and Shibuno 2010). Incorporating coral cover into the function of the observed SAR only slightly increased the coefficient of determination, likely because of low overall coral cover $(26.2 \%)$.

Drifting larvae of resident coral reef fish are often thought to settle on patch reefs at a probability proportional to the reef area. Belmaker et al. (2007) showed that observed SARs in coral reef fish can be explained by a random placement model alone. The present study, however, found that observed species richness on the largest reefs were more than two standard deviations from expected values determined by RPMS. Furthermore, expected species richness (13.5) extrapolated from logarithmic regressions of the total patch reef area was much lower than the observed total species richness (21.5). Thus, our results indicate that observed SARs cannot be fully explained by a random placement model. In contrast, expected species richness extrapolated from the cubic regression curve fitted to the RPMS data (23.0 species) was similar to the observed total species richness. It is probable that the accuracy of the RPMS estimation of total species richness was caused by the preponderance of data from small and medium-sized reefs, where the few large reefs that occurred likely had a negative effect on total species richness. As such, the probability of a fish larva reaching a reef may not be proportional to reef area. Nonrandom recruitment of juveniles to a habitat patch has been reported for some coral reef fish species (Elliott et al. 1995; Schmitt and Holbrook 1999; Hattori 2012). For example, residents chase newly settled juveniles of Dascyllus species out of the branching corals and sea anemones they inhabit when shelter space is insufficient (Schmitt and Holbrook 1999). Furthermore, aggressive behavior in dominant fish keeps inferior competitors at the edges of the habitat patch where predation risk may be high (Holbrook and Schmitt 2002). Thus, even if juveniles settle at random, recruitment may not be random because of aggressive behavior by residents, high predation pressure at habitat edges and post-settlement movement.

Reduced space in flat reefs relative to tall reefs may result in stronger effects of interspecific competition on species richness (Hattori and Shibuno 2013). Consequently, relatively flat reefs may be unable to harbor as many species as expected based on RPMS using reef area. Large reefs are unlikely to be tall for their size in shallow back reefs (Hattori and Shibuno 2013), whereas a patch reef in a deeper area may grow allometrically according to Volume $=\mathrm{c} \times$ Area $^{1.5}$, where $\mathrm{c}$ is the coefficient. At our shallow study site (1.5-2.5 m depth), volume was calculated as $83.331 \times$ Area $^{1.3132}$ $\left(\mathrm{R}^{2}=0.9717, n=84\right)$ or as $194.79 \times$ Area -91.854 $\left(\mathrm{R}^{2}=0.9926, n=84\right)$. Because large reefs likely ex- tended nearly to the surface of the water, patch reef volume was a better determinant of species richness than patch reef area. Thus, logarithmic regression functions on the observed SVRs provided the best estimates of patch reef species richness. Although total species richness could not be predicted from the observed SVR alone, estimates based on SVR regression curves fitted to the RPMS data were better (in AIC comparisons) than those estimated the same way using SAR. Thus, given a nearly identical total area, several small but tall reefs may harbor a greater number of species than a large flat reef, indicating important effects of SLOSS in shallow back reefs at the small scale. In deeper waters, such as the outer fringing reef, total reef area irrespective of the size distribution of patches is likely to be a useful indicator of species richness (as in Belmaker et al. 2007) because large patch reefs can be tall enough.

Patchy habitats have been found to enhance species coexistence through interspecific trade-offs between dispersal (colonization) and competitive abilities (Tilman 1994; Lehman and Tilman 1997). For example, two competing anemonefishes (Amphiprion clarkii and $A$. perideraion) that use the same sea anemone species as habitat can coexist through differences in preferred habitat sizes. The superior competitor A. perideraion occupies only a few of the largest anemones, while the superior disperser $A$. clarkii can inhabit and move between anemones of various sizes (Hattori 1995, 2002). Moreover, juvenile $A$. perideraion can recruit to large anemones already inhabited by $A$. clarkia and eventually replace $A$. clarkia, but $A$. clarkii can escape intra- and interspecific competition by occupying many anemones during its lifetime (Hattori 1994, 2002). Of the eight most abundant species in our study, $C$. viridis and $S$. lividus, which occupied only $\sim 25 \%$ of the reefs surveyed, may be superior competitors. C. cyanea, D. aruanus, $P$. adelus and S. nigricans inhabited more than half of the reefs and thus may be superior dispersers. As aggressive territorial herbivores, S. nigricans and S. lividus rarely coexisted on patch reefs at the study site, except for on large tall reefs (Hattori and Shibuno 2013). In the absence of large tall reefs, however, these two species may still coexist because $S$. nigricans is a superior disperser. Of the four most abundant planktivores, $C$. viridis and $D$. aruanus both inhabit branching corals. Our results indicate that the two species rarely coexist on a small branching coral but are widely distributed because $D$. aruanus can settle on branching corals unoccupied by $C$. viridis. Further studies are needed to determine the effects of varying patch reef size on interspecific trade-offs between dispersal and competitive abilities at small scales (Tilman 1994; Lehman and Tilman 1997) and the implications for species richness of coral reef fish.

Habitat complexity has been shown to counteract the negative effects of interspecific competition and predation on resident species and thus contribute to the high species richness of coral reef fish at a number of scales (e.g., Luckhurst and Luckhurst 1978; Bell and Galzin 
1984; Jones and Syms 1998). Structural complexity has been measured using a number of parameters, including the number of crevices or holes, the ratio of chain length to linear distance across the reef, and the abundance of live coral cover (e.g., Luckhurst and Luckhurst 1978; Bell and Galzin 1984; Sano et al. 1987; McCormick 1994; Chabanet et al. 1997). Consequently, many studies have reported a strong positive relationship between reef substrate complexity and fish species richness. Microscale indices of habitat complexity, however, may be impractical for evaluating coral reef habitat quality because of the difficulty of taking such measurements, even in a small area. Furthermore, because of their limited scope of applicability, these indices cannot be used to examine habitat patch dynamics. Instead, coral-generated meso-scale rugosity may be a better indicator of coral reef fish abundance and diversity (Harborne et al. 2012), as tall coral patches ( $>0.5 \mathrm{~m}$ height) have a higher carrying capacity for some coral reef fishes. Hattori and Kobayashi $(2007,2009)$ also suggested that small but tall patch reefs $(>0.5 \mathrm{~m}$ height $)$ can provide sufficient habitat for anemonefishes in the shallow back reef. Patch reef height and area can easily be determined using fine-scale seascape maps created from high resolution aerial photographs and image analysis software without the need for GPS. These methods can be used to calculate patch reef volume over larger areas (on the scale of hectares), allowing the investigation of habitat patch dynamics.

Although indices of meso-scale rugosity do not reflect microscale topographic complexity, and all patch reefs do not have cylindrical shapes, summed patch reef volume provides a rough estimate of the total amount of essential habitat over larger scales. These estimates include the water column above the reef and the surface area and internal space of the reef. As many reef fish species remain in the internal space of the reef while feeding on plankton in the overlying water or on benthic organisms on the reef surface, the summed patch reef volume may be a useful indicator of total species richness relative to the total amount of essential habitat. Unmanned aerial vehicles or drones that can fly at very low altitude may soon provide coral reef ecologists with high-resolution aerial photographs over large areas (Anderson and Gaston 2013). Land reclamation for the construction of piers, roads, airports, industrial sites, and waterfronts is a common cause of destruction of shallow back reef habitat, particularly in densely populated islands such as Okinawa, Japan (Spalding et al. 2001; Tsuchiya et al. 2004; Hattori and Kobayashi 2007, 2009; Hattori and Shibuno 2010, 2013). The destruction of habitat by land reclamation as well as by coral bleaching has resulted in reduced coral reef fish diversity and abundance (Spalding et al. 2001; Roberts et al. 2002; Tsuchiya et al. 2004). Habitat quality assessment is essential to prioritize protection measures. Three-dimensional meso-scale rugosity is a simple index of habitat complexity that can be made at the scale of an entire shallow back reef. Thus, this study suggests that high-resolution aerial photographs and the meso-scale rugosity index can and should be used for selecting high priority sites for marine protected areas, particularly when financial resources are limited and all sites cannot be protected.

Acknowledgments We are grateful to David Price and anonymous reviewers for valuable advice on the manuscript. Fumitoshi Iwasaki provided assisted with the references. This work was supported in part by Grants-in-Aid for Science Research from the Japan Ministry of Education, Culture, Sports, Science and Technology (nos. 23570022, 20570020, 15K07218). A. H. is an Affiliated Scientist at the Center for Ecological Research, Kyoto University.

Open Access This article is distributed under the terms of the Creative Commons Attribution 4.0 International License (http:// creativecommons.org/licenses/by $/ 4.0 /$ ), which permits unrestricted use, distribution, and reproduction in any medium, provided you give appropriate credit to the original author(s) and the source, provide a link to the Creative Commons license, and indicate if changes were made.

\section{References}

Acosta CA, Robertson DN (2002) Diversity in coral reef fish communities: the effects of habitat patchiness revisited. Mar Ecol Prog Ser 227:87-96

Allen GR (1991) Damselfishes of the world. Mergus Publications, Melle

Almany GR, Berumen ML, Thorrold SR, Planes S, Jones GP (2007) Local replenishment of coral reef fish populations in a marine reserve. Science 316:742-744

Anderson K, Gaston KJ (2013) Lightweight unmanned aerial vehicles will revolutionize spatial ecology. Front Ecol Environ 11:138-146

Ault TR, Johnson CR (1998) Spatially and temporally predictable fish communities on coral reefs. Ecol Monogr 68:25-50

Bell JD, Galzin R (1984) Influence of live coral cover on coral-reef fish communities. Mar Ecol Prog Ser 15:265-274

Belmaker J, Ben-Moshe N, Ziv Y, Shashar N (2007) Determinants of the steep species-area relationship of coral reef fishes. Coral Reefs 26:103-112

Boström C, Pittman SJ, Simenstad C, Kneib RT (2011) Seascape ecology of coastal biogenic habitats: advances, gaps, and challenges. Mar Ecol Prog Ser 427:191-217

Chabanet P, Ralambondrainy H, Amanieu M, Faure R, Galzin R (1997) Relationships between coral reef substrata and fish. Coral Reefs 16:93-102

Chave EH, Eckert DB (1974) Ecological aspects of the distributions of fishes at Fanning Island. Pac Sci 28:297-317

Chittaro PM (2002) Species-area relationships for coral reef fish assemblages of St. Croix, US Virgin Islands. Mar Ecol Prog Ser 233:253-261

Christie MR, Tissot BN, Albins MA, Beets JP, Jia Y, Ortiz DM, Thompson SE, Hixon MA (2010) Larval connectivity in an effective network of Marine Protected Areas. PLoS ONE 5:e15715

Coleman BD (1981) On random placement and species-area relations. Math Biosci 54:191-215

Dengler J (2009) Which function describes the species-area relationship best? A review and empirical evaluation. J Biogeogr 36:728-744

Elliott JK, Elliott JM, Mariscal RN (1995) Host selection, location, and association behaviors of anemonefishes in field settlement experiment. Mar Biol 122:377-389

Fahrig L (2013) Rethinking patch size and isolation effects: the habitat amount hypothesis. J Biogeogr 40:1649-1663 
Harborne AR, Mumby PJ, Ferrari R (2012) The effectiveness of different meso-scale rugosity metrics for predicting intra-habitat variation in coral-reef fish assemblages. Environ Biol Fish 94:431-442

Hattori A (1994) Inter-group movement and mate acquisition tactics of the protandrous anemonefish, Amphiprion clarkii, on a coral reef, Okinawa. Jpn J Ichthyol 41:159-165

Hattori A (1995) Coexistence of two anemonefish, Amphiprion clarkii and $A$. perideraion, which utilize the same host sea anemone. Environ Biol Fish 42:345-353. doi:10.1007/BF00001464

Hattori A (2002) Small and large anemonefishes can coexist using the same patchy resources on a coral reef, before habitat destruction. J Anim Ecol 71:824-831. doi:10.1046/j.1365-2656. $2002.00649 x$

Hattori A (2012) Determinants of body size composition in limited shelter space: why are anemonefishes protandrous? Behav Ecol 23:512-520. doi:10.1093/beheco/arr217

Hattori A, Kobayashi M (2007) Configuration of small patch reefs and population abundance of a resident reef fish in a complex coral reef landscape. Ecol Res 22:575-581. doi:10.1007/s11284006-0054-4

Hattori A, Kobayashi M (2009) Incorporating fine-scale seascape composition in an assessment of habitat quality for the giant sea anemone Stichodactyla gigantea in a coral reef shore zone. Ecol Res 24:415-422. doi:10.1007/s11284-008-0518-9

Hattori A, Shibuno T (2010) The effect of patch reef size on fish species richness in a shallow coral reef shore zone where territorial herbivores are abundant. Ecol Res 25:457-468. doi: 10.1007/s11284-009-0675-5

Hattori A, Shibuno T (2013) Habitat use and coexistence of three territorial herbivorous damselfish on different-size patch reefs. J Mar Biol Ass UK 93:2265-2272. doi:10.1017/ S0025315413000829

Holbrook SJ, Schmitt RJ (2002) Competition for shelter space causes density-dependent predation mortality in damselfishes. Ecology 83:2855-2868

Jones GP, Syms C (1998) Disturbance, habitat structure and the ecology of fishes on coral reefs. Austral J Ecol 23:287-297

Lehman CL, Tilman D (1997) Competition in spatial habitats. In: Tilman D, Kareiva P (eds) Spatial ecology: the role of space in population dynamics and interspecific interactions. Princeton University Press, Princeton, pp 185-203

Lowe-McConnell RH (1987) Ecological studies in tropical fish communities. Cambridge University Press, Cambridge

Luckhurst BE, Luckhurst K (1978) Analysis of the influence of substrate variables on coral reef fish communities. Mar Biol 49:317-323

McClanahan TR (1994) Kenyan coral reef lagoon fish: effects of fishing, substrate complexity, and sea urchins. Coral Reefs $13: 231-241$

McCormick MI (1994) Comparison of field methods for measuring surface topography and their associations with a tropical reef fish assemblage. Mar Ecol Prog Ser 112:87-96

Mumby PJ, Elliott IA, Eakin CM, Skirving W, Paris CB, Edwards HJ, Enríquez S, Iglesias-Prieto R, Cherubin LM, Stevens JR (2011) Reserve design for uncertain responses of coral reefs to climate change. Ecol Let 14:132-140

Pinsky ML, Palumbi SR, Andréfouët S, Purkis SJ (2012) Open and closed seascapes: where does habitat patchiness create populations with high fractions of self-recruitment? Ecol Appl $22: 1257-1267$
Pittman SJ, McAlpine CA, Pittman KM (2004) Linking fish and prawns to their environment: a hierarchical landscape approach. Mar Ecol Prog Ser 283:233-254

Pittman SJ, Kneib RT, Simenstad CA (2011) Practicing coastal seascape ecology. Mar Ecol Prog Ser 427:187-190

Planes S, Jones GP, Thorrold SR (2009) Larval dispersal connects fish populations in a network of marine protected areas. P Natl Acad Sci USA 106:5693-5697

R Development Core Team (2013) R: a language and environment for statistical computing. R Foundation for Statistical Computing, Vienna, Austria. http://www.R-project.org

Ries L, Sisk TD (2010) What is an edge species? The implications of sensitivity to habitat edges. Oikos 119:1636-1642

Roberts CM, McClean CJ, Veron JEN, Hawkins JP, Allen GR, McAllister DE, Mittermeier CG, Schueler FW, Spalding M, Wells F, Vynne C, Werner TB (2002) Marine biodiversity hotspots and conservation priorities for tropical reefs. Science 295:1280-1284

Roff JC, Zacharias MA (2011) Marine conservation ecology. Earthscan Ltd., London

Rosenzweig ML (1995) Species diversity in space and time. Cambridge University Press, Cambridge

Rosenzweig ML (2004) Applying species-area relationships to the conservation of species diversity. In: Lomolino MV, Heaney LR (eds) Frontiers of biogeography: new directions in the geography of nature. Sinauer Association Inc., Sunderland, pp 325-343

Sale PF (1991) The ecology of fishes on coral reefs. Academic Press, San Diego

Sale PF (2002) Coral reef fishes: dynamic and diversity in a complex ecosystem. Academic Press, San Diego

Sale PF, Steel WJ (1986) Random placement and the distribution of fishes among coral patch reefs. Mar Ecol Prog Ser 28:165-174

Sano M, Shimizu M, Nose Y (1987) Long-term effects of distribution of hermatypic corals by Acanthaster planci infestation on reef fish communities at Iriomote Island, Japan. Mar Ecol Prog Ser 35:267-275

Schmitt RJ, Holbrook SJ (1999) Settlement and recruitment of three damselfish species: larval delivery and competition for shelter space. Oecologia 118:76-86

Simberloff D, Gotelli N (1984) Effects of insularization on plant species richness in the prairie-forest ecotone. Biol Conserv 29:27-46

Smith AB (2010) Caution with curves: caveats for using the speciesarea relationship in conservation. Biol Conserv 143:555-564

Spalding MD, Ravilious C, Green EP (2001) World atlas of coral reefs. University of California Press, Berkeley

Tamura H, Nadaoka K, Paringit EC (2007) Hydrodynamic characteristics of a fringing coral reef on the east coast of Ishigaki Island, southwest Japan. Coral Reefs 26:17-34

Tilman D (1994) Competition and biodiversity in spatially structured habitats. Ecology 75:2-16

Tjörve E (2003) Shapes and functions of species-area curves: a review of possible models. J Biogeogr 30:827-835

Tsuchiya M, Nadaoka K, Kayane H, Yamano H (2004) Coral Reefs of Japan. Ministry of the Environment, Japan, Tokyo 